\title{
A Task-Centered Approach to Treatment Planning
}

\author{
Williạm R. Dahms \\ University of Michigan
}

It is a maxim in residential programs that effective treatment needs to be based upon carefully developed plans. The reality, however, is that treatment plans seldom have much impact. This paper describes how the staff at one residential center developed a comprehensive yet comprehensible model for treatment planning that moved the plans out of the file cabinets and onto the front lines.

The setting for this process was Starr Commonwealth for Boys, Junior Campus, a small residential treatment program serving 44 behavior-disordered, delinquent youth, ages 10 to 14 . Staff function on interdisciplinary teams that include child care workers, teachers, and social workers. In a program that uses behavior modification, group counseling, special education, and intervention in the home-community-school ecology, these staff focused their efforts on developing a method of treatment planning that would take these diverse and disparate treatment approaches and weave them into a unified treatment experience for each youth.

\section{Pitfalls in Treatment Planning}

An evaluation of our past efforts at planning treatment pointed up a number of serious problems. Many treatment team members had only a vague idea about the specific treatment goals for each youth. While most team members had a general understanding of the kinds of problems that certain youth were presenting, they frequently lacked

Requests for reprints should be sent to William R. Dahms, 1143 McIntyre, Ann Arbor, Michigan 481.05. The author wishes to thank Larry Brendtro and Howard Garner for their helpful suggestions during the preparation of this paper. 
the specific, immediate knowledge to answer the question: What are the objectives for this boy, this week, or this month, on which we as a treatment team are going to focus?

Many treatment team members also did not know the ultimate goal of treatment for a given youngster. Answers to the difficult questions relating to the viability of a youth's home, foster placement, or group home living were being put off to the last possible moment. For youngsters who were not returning home, spending $80 \%$ of the time in placement without a clear decision on postplacement planning was not unusual. Uncertainty was a feature for both youth and team.

Boys did not understand their treatment plans. Many did not even know that there were such things. For those who did know about treatment plans and had seen them, it was a rare youngster indeed who could comprehend the professional social work jargon.

Because they had no well-defined goals, boys did not feel a sense of purpose and direction. They were unsure of which issues had been resolved and which were yet to face them as their treatment continued. Lacking a cutting edge to their treatment experience, youngsters perceived the treatment process as a nebulous "something" that typically lasted a year and was marked by starts, stops, and irregular surges of energy and motivation.

Community service staff were having difficulty helping parents understand the treatment process. The ostensible purpose for having a community service function was to share with parents facts and information regarding the youngster and his treatment and to draw the parents into the process of change. The same barriers to understanding that marked the experience of many staff and boys impeded effective liaison work with parents.

A final telling point was that treatment plans were usually out of date. That fact could have led to a number of inferences, but there was at least one that was inescapable: Simply put, staff did not consider treatment plans to be very useful.

\section{Blueprint for Change}

On the basis of the foregoing evaluation of past treatment planning, it was agreed that:

1. Treatment plans should be written in language that would make them understandable to boys, staff, parents, and referral agency personnel.

2. Treatment plans should have relevance and utility for front-line staff.

3. Treatment plans should incorporate information from the home-schoolcommunity ecology. 
4. Treatment plans should incorporate input from the treatment team, the youth's group, and from the youngster himself.

5. Treatment plans should specify clear goals, methods to reach those goals, and criteria to assess goal achievement.

The flow chart in Figure 1 shows the process used by treatment teams to develop and guide the treatment experience for each youth. Treatment planning and implementation incorporate the following aspects:

- ASSESSING PROBLEMS. This should include not only the perspective of residential staff, but also a careful assessment of the problem that led to placement. Community service staff interviews with the youth's parents, teachers, relatives, probation officers, and significant others are pivotal in identifying these peer, school, and home problems.

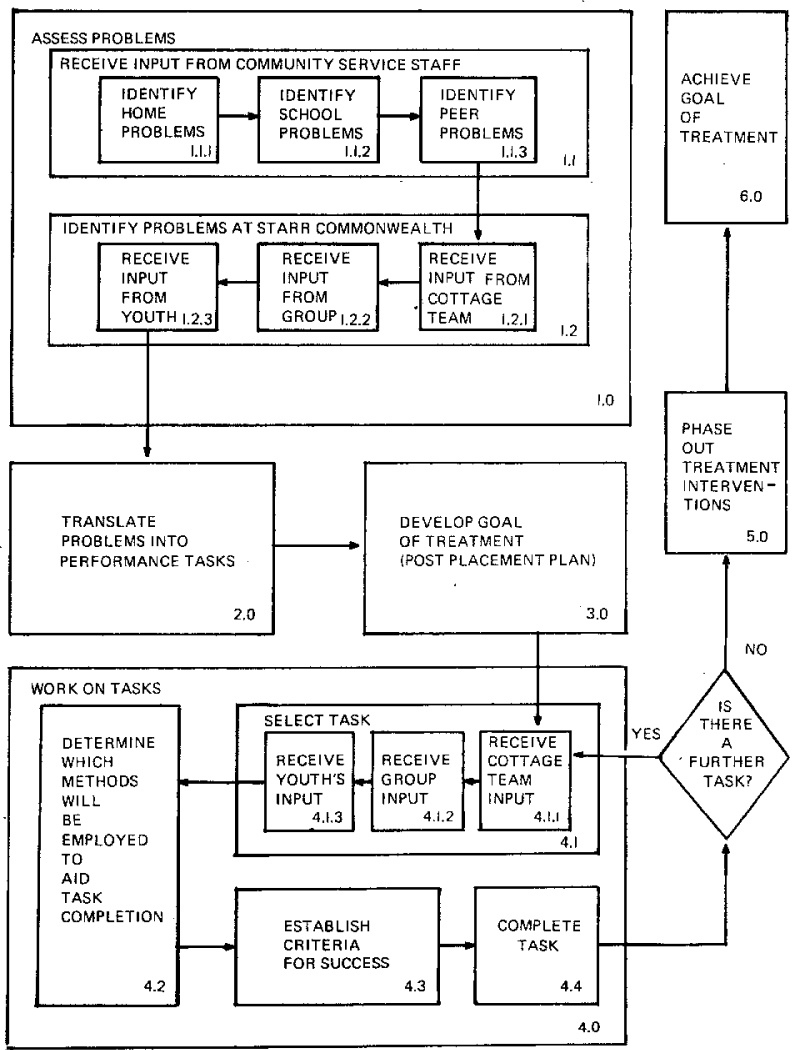

FIGURE 1. Flow chart of treatment planning process. 
- DEVELOPING PERFORMANCE TASKS. Each performance task is a direct derivative of a specific problem identified in the prior step.

- DEVELOPING GOAL OF TREATMENT. It is extremely valuable to have a specific postplacement plan identified before youth begin to work on their tasks.

- WORKING ON TASKS. Small group problem-solving sessions, as well as cottage group counseling, provide opportunities for staff to elicit peer perspective on any given youth's problems. Incorporating this perspective can and should be a part of defining the problems, establishing task priority, and selecting the methods used to aid task completion.

- PHASING OUT TREATMENT INTERVENTIONS. In anticipation of return to the community, plans must be developed to reduce the youth's reliance on the program.

- ACHIEVING GOAL OF TREATMENT. Youth returns to the community as specified in the postplacement plan.

Use of the flow chart was an important aid for many staff in helping them conceptualize the process of treatment. They became sensitized to the many different factors that must be taken into consideration to design and implement effective treatment plans.

\section{A Model Treatment Plan}

The end product of our efforts at treatment planning was the creation of a format tailored to the individual needs of each youth. One such treatment plan is presented in Figure 2, as it appeared around the middle of the treatment process.

A treatment plan is put together for each youth during the first 45 to 60 days in placement. The exact number of tasks to be developed requires a very careful decision. Typically no more than a dozen of the most important issues are designated for attention. It is important to avoid confronting a failure-prone youngster with an unmanageable number of tasks.

Each task begins with the words, "To learn how to ....," reflecting the learning theory perspective of the treatment program. The implicit assumption is that all behavior is learned. On that assumption, the treatment process becomes one of analyzing the situational determinants that maintain delinquent or maladaptive behaviors and developing treatment tasks that help youth unlearn old habits and ineffective styles of interaction and learn more effective ways of relating to, and coping with, the world around them.

The priority of tasks is decided jointly by youth and treatment 

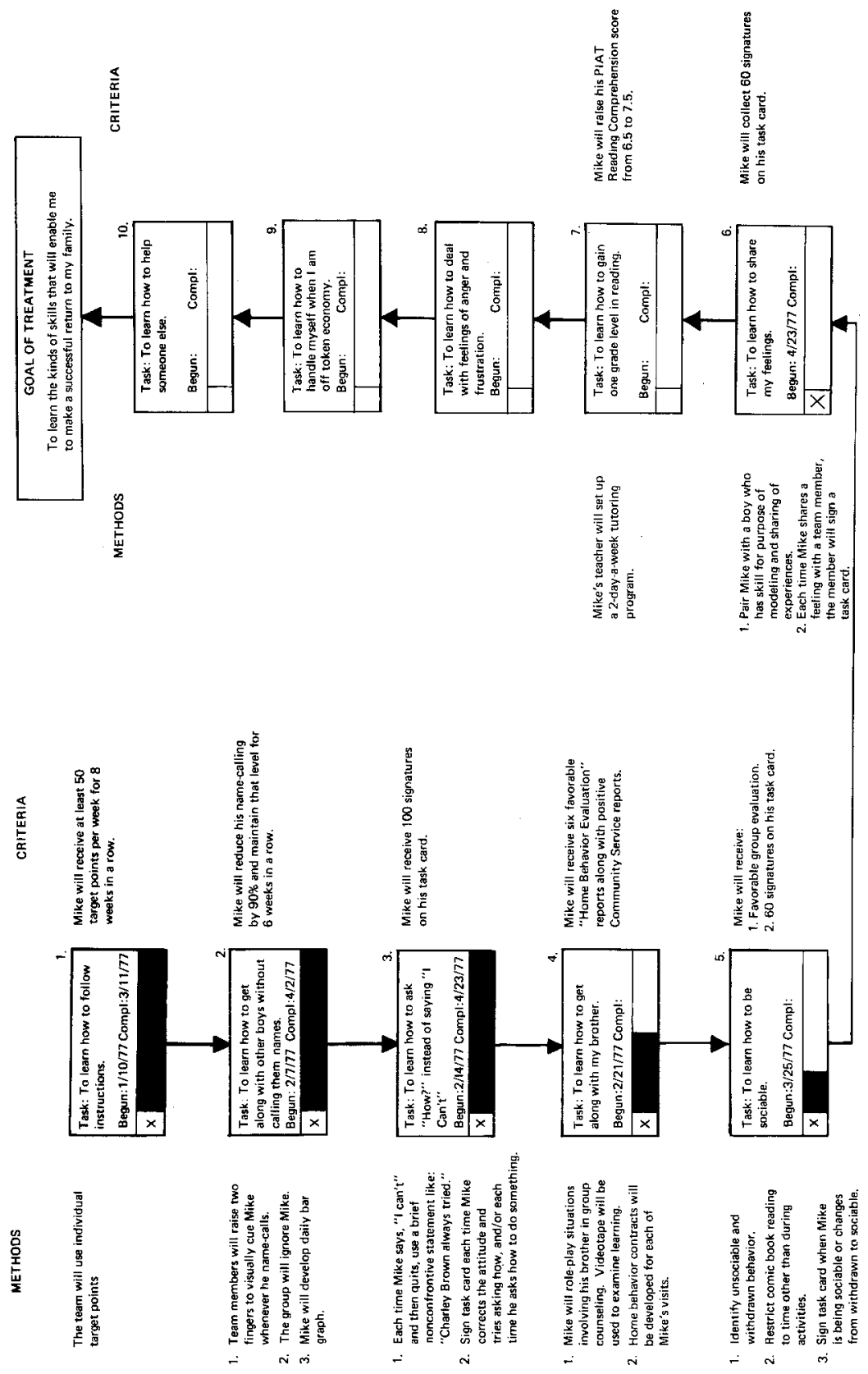
team. The concrete, specific tasks tend to come first, with the more abstract, conceptual issues being dealt with later. When a task or tasks are being worked on, an " $\mathrm{X}$ " is placed in the lower left-hand corner of the task box. The shaded area in the lower portion of each box reflects the amount of progress a youngster has made toward the accomplishment of a given task at a particular point in time.

The statements to the left of each task box identify the methods that the treatment team will employ to support the youth in his effort to accomplish a given task. The criteria for success are indicated to the right of each task box and are clear answers to the question that youth are presumed to have regarding each task: "How will I know when I have accomplished it?"

Task accomplishment or completion has to be recognized as a treatment technique or process rather than as a finished act. Learning to deal with feelings of anger and frustration (Task 8), for example, is an ongoing human struggle. Teaching a youngster to get along with his brother (Task 4) is probably not something that can begin in February and end in May.

Ultimately, in developing a model for treatment planning that must both guide and reflect the treatment process, the question that has to be dealt with is: How should the process of change be conceptualized, i.e., how should staff, youth, and parents think and talk about what they are doing and experiencing? There are a number of possible answers to this question, many of which might be very useful. Conceptualizing the process of change as a series of tasks, each of which can in some sense be started and completed on specified dates, is one approach that has proved useful in effecting change in the lives of troubled youth. For example, providing youngsters with a success experience in taking one more step toward gaining emotional competence (Task 8) and social competence (Task 5) can breed further confidence and success as the youngsters transfer learning back into the community.

The number of tasks that a given youngster works on at any particular time varies from youth to youth. The treatment team must decide how many tasks a youngster can work on without his attention and energy being spread too thinly. Requiring a certain amount of accomplishment on one or more tasks before a youngster begins subsequent tasks is one way of modulating the quantity and quality of progress.

The youth, his family, referral agency personnel, each treatment team member, and the community services worker all have current 
team member, and the community services worker all have current copies of the treatment plan. Each time community service staff make contact with the agency and family, reference to progress or the lack of it is made, using the visual reinforcement that the treatment plan format provides.

A graduation date is projected and becomes an explicit, written part of the goal of treatment after youngsters have completed 50 percent of their tasks. Having thus earned the right to a targeted release or graduation date, the youth is given more responsibility for achieving the treatment goal on or ahead of schedule.

Treatment plans incorporate personal, academic, and home-related issues. For parents and agency personnel, an important aspect of each community service contact is the developing and refining of the kinds of involvement and support that will be available to aid youth on home-related tasks. While in placement, youth have regularly scheduled home passes to work on treatment tasks. Thus, the process of treatment weaves together experiences both at home and on campus that provide varied opportunities for change.

Parents who are part of a treatment process that is devoid of mystery are better able to become active and empathic participants. Community service staff have a tool that can play a significant role in attacking the sense of powerlessness that is common to parents of youth in placement. Simply by leaving parents with the feeling that they know what is happening, these plans can do a great deal to elicit cooperation. Having a plan that asks them to assume a role parallel to that of residential staff imparts a sense of importance as they share responsibility with members of the treatment team.

Youth, who always have access to their treatment plans, can use them to determine or clarify where they are, where they've been, and where they are going. The arrangement of the task boxes in a ladder makes visual and visceral sense. Use of a form and format that implicitly puts the responsibility for upward progress on the youth himself motivates enthusiastic participation. Each step forward enhances the growth of a self-concept in which youth begin to see themselves as people who can succeed, who can accomplish, and who have a promising future. A clear sense of purpose and direction is an inherent part of that process.

Referral agency personnel appreciate having a system that gives clear answers to their how, what, and when questions regarding treatment. Routinely overworked, they are grateful for a format that gives them a "sense of the situation" in one brief scan. The system reduces surprises, enhances predictability, and elicits better support and co- 
operation when the agency has to respond to treatment team recommendations.

The advent of a task-centered approach to treatment planning has meant many things to treatment staff. The increased availability and understandability of the plans have fostered more creativity. Treatment plans are being used increasingly to guide team behavior, to elicit meaningful involvement from all staff, to encourage a broad treatment perspective, to stimulate the right kinds of questions, and to develop a common language among participants in the treatment process-in short, to make the benefits of teamwork a reality. 